\title{
Broiler performance and bone strength minimally affected by either a simulated dusk or night-interruption photoperiod
}

\author{
P.D. Lewis ${ }^{1 \#}$, R.M. Gous ${ }^{1}$ and E. Tumova ${ }^{2}$ \\ ${ }^{1}$ Animal and Poultry Science, School of Agricultural Sciences and Agribusiness, University of KwaZulu-Natal, \\ Scottsville 3209, South Africa \\ ${ }^{2}$ Czech University of Life Sciences Prague, 16521 Prague 6 - Suchdol, Czech Republic
}

\begin{abstract}
Two genotypes of male broilers were given $12 \mathrm{~h}$ of daily illumination; as a conventional photoperiod, with the final hour at reduced illuminance to simulate dusk, or with $1 \mathrm{~h}$ of the light given during the middle of the night. The lighting modifications had no significant effect on any performance variable or on tibial breaking strength. Feed intake was unaffected by the lighting treatments during either the 1-h dusk period or the night, but was inexplicably stimulated in the both experimental groups during the main photoperiod.
\end{abstract}

Keywords: Photoperiod, dusk, broiler growth, bone strength

\# Corresponding author. E-mail: pdlewis@dsl.pipex.com

\section{Introduction}

Broilers have commonly been reared on 23-h photoperiods, but from June 2010 new EU welfare regulations (Minimum rules for the protection of chickens kept for meat production) will prohibit, within the EU and from $7 \mathrm{~d}$ of age, the use of daylengths longer than $18 \mathrm{~h}$. In two recent studies, in which the photoperiodic response of two genotypes of broiler was assessed between $2 \mathrm{~h}$ and constant illumination, growth was optimised, mortality was minimised, and tibial breaking strength was maximised by providing a 12-h photoperiod (Lewis et al., 2009a; b); furthermore, the birds consumed more than $20 \%$ of their daily feed intake during the 12-h night. In contrast, performance in previous studies has consistently been inferior for broilers exposed to 12-h daylengths (Sqibb \& Collier, 1979; Ingram et al., 2000; Brickett et al., 2007) and minimal feeding activity has occurred during the dark period (Savory, 1976; Sqibb \& Collier, 1979). Feed intake and body weight gain during the first $21 \mathrm{~d}$ in these recent trials was, as observed in the early studies, inferior to birds exposed to $>12-\mathrm{h}$ photoperiods, though the differences had disappeared by $35 \mathrm{~d}$ (typical slaughter age for male broilers in South Africa). Savory (1976) reported that the provision of a 'dawn' and 'dusk' within a 12-h photoperiod resulted in an increased feed intake, and faster and more efficient growth, whilst Classen et al. (2004) noted that providing $12 \mathrm{~h}$ of darkness in more than one scotoperiod also stimulated feed intake and growth rate relative to birds given a single 12-h dark period, particularly in the first $14 \mathrm{~d}$. The current study investigated the possibility that the performance of broilers given $12 \mathrm{~h}$ illumination per day could be enhanced, particularly during the early stages of growth, by providing a 1-h simulated 'dusk' or fragmenting the 12-h night to increase feed consumption. The nocturnal activity stimulated by the night-interruption lighting might also have improved tibial breaking strength.

\section{Materials and Methods}

Cobb '500' and Ross '308' male broilers, which had been vent sexed for accuracy, were placed at $1 \mathrm{~d}$ of age on the litter floor in each of nine lightproof rooms. Each room was divided by a mesh fence into two pens, and 220 Cobb or 220 Ross birds placed in each pen at a stocking density of $9.2 / \mathrm{m}^{2}$. All birds were given constant illumination for the first day then three rooms were randomly allocated to each of three lighting regimens: 12L:12D (12L); 11L:1dim:12D (Dim), 11L:5D:1L:7D (NI), so 3 lighting treatments x 2 breeds $\times 3$ rooms $\times 220$ birds $=3960$ birds in total. In each pen, light was provided by two $11 \mathrm{~W}$ compact warm-white fluorescent lamps located $1.8 \mathrm{~m}$ above the floor, giving a mean illuminance of $24 \pm 1.6$ lux at a height of $20 \mathrm{~cm}$. In the three rooms given the Dim treatment, light during the final hour of the photoperiod was supplied by a single $11 \mathrm{~W}$ compact warm-white fluorescent lamp in each room, with foil wrapped around the lamp to reduce the light output to give a mean illuminance of $5 \pm 0.8$ lux ( 0.22 of normal illuminance). 
All groups received $1 \mathrm{~kg} /$ bird of a proprietary broiler starter crumb (12.8 MJ ME/kg; $200 \mathrm{~g}$ crude protein $/ \mathrm{kg}$ ) followed by a proprietary broiler grower pellet (12.8 MJ ME/kg; 160 g crude protein $/ \mathrm{kg}$ ). The feed was provided on open trays for the first $7 \mathrm{~d}$, and in circular hanging tubular feeders thereafter.

Sixty birds per pen were randomly sampled and bulk weighed at 7, 14, 21 and $28 \mathrm{~d}$ of age, and all birds bulk weighed at $35 \mathrm{~d}$. Feed was weighed back at 7-d intervals (intake calculated on surviving bird basis), and mortality and culls were removed daily and subjectively examined for signs of leg abnormality or Sudden Death Syndrome (SDS). Leg abnormalities included valgus and varus deformation of the intertarsal joint, swollen hocks (dyschondroplasia), rotated tibia, and, in live birds, inability to walk, whilst SDS was indicated by the bird being found in good condition on its front or back with legs outstretched. Feed weigh-backs were conducted in three rooms (one room per treatment) over a 24-h period at 25/26 d and from a different three rooms at 32/33 d of age to determine the feed consumed during the first $11 \mathrm{~h}$ of the photoperiod, during the $12^{\text {th }}$ hour of the photoperiod in the $12 \mathrm{~L}$ and Dim rooms, and during the 12-h night.

Both tibiae were removed from the carcasses immediately after the birds had been killed by cervical dislocation, and stored at $-16{ }^{\circ} \mathrm{C}$. After thawing, the tibiae were stripped of muscle and weighed. Breaking strength $(\mathrm{kg})$ was determined using a three-point loading test, with the supports set $40 \mathrm{~mm}$ apart and a vertical hydraulic force applied at the midpoint of the bone shaft; the peak force required to break the bone was recorded on a tensometer (loadcell - Loadtech, South Africa; digital display - Red Lion Controls, USA).

All performance data (mortality, SDS, and leg abnormalities were shown by a Shapiro-Wilk Normality test not to be normally distributed and arcsine transformed prior to further analysis) were subjected to a splitplot ANOVA with lighting as the main plot, genotype as the subplot, and significant differences between means $(\mathrm{P}<0.05)$ identified using a Student's $t$-test, with Room*Light as the error term for lighting treatment and Room*Light*Genotype for genotype (Analytical Software, 2003). Feeding behaviour data were analysed using a factorial design of ANOVA with monitoring age as the blocked variable and light and genotype as the treatment variables.

\section{Results}

Data in Table 1 show that there were no significant differences between lighting treatments for feed intake, body weight gain or feed conversion efficiency at any age, nor in the European Efficiency Factor (EEF) to $35 \mathrm{~d}$. With the exception of Cobb's superior feed conversion efficiency over Ross during the first 7 d, there were no significant differences between the genotypes at any stage for feed intake, body weight gain, feed conversion efficiency, or EEF. There were no significant differences between lighting treatments or

Table 1 Mean feed intake, body weight gain, and feed conversion ratio $0-7 \mathrm{~d}, 8-14 \mathrm{~d}$ and 0 - $35 \mathrm{~d}$, and European Efficiency Factor to $35 \mathrm{~d}$ for Cobb '500' and Ross '308' males given $12 \mathrm{~h}$ bright light (12L:12D), $11 \mathrm{~h}$ bright and $1 \mathrm{~h}$ dim light (11L:1dim:12D), or $11 \mathrm{~h}$ bright with a 1-h photoperiod interrupting the night (11L:5D:1L:7D)

\begin{tabular}{|c|c|c|c|c|c|c|c|c|c|c|}
\hline \multirow{2}{*}{$\begin{array}{l}\text { Lighting } \\
\text { treatment }\end{array}$} & \multicolumn{3}{|c|}{$\begin{array}{l}\text { Feed intake } \\
\quad(\mathrm{g})\end{array}$} & \multicolumn{3}{|c|}{$\begin{array}{l}\text { Body weight gain } \\
\text { (g) }\end{array}$} & \multicolumn{3}{|c|}{$\begin{array}{c}\text { Feed conversion } \\
\text { (g BW gain/kg feed) }\end{array}$} & \multirow{2}{*}{$\begin{array}{l}\text { European } \\
\text { Efficiency } \\
\text { Factor }^{1}\end{array}$} \\
\hline & $0-7 \mathrm{~d}$ & $8-14 \mathrm{~d}$ & $0-35 d$ & $0-7 \mathrm{~d}$ & $8-14 \mathrm{~d}$ & $0-35 d$ & $0-7 \mathrm{~d}$ & $8-14 \mathrm{~d}$ & $0-35 d$ & \\
\hline 12L:12D & 130 & 468 & 3548 & 117 & 272 & 2117 & 901 & 582 & 597 & 333 \\
\hline 11L:1dim:12D & 130 & 461 & 3586 & 115 & 269 & 2168 & 881 & 584 & 600 & 335 \\
\hline 11L:5D:1L:7D & 131 & 464 & 3578 & 117 & 278 & 2160 & 889 & 599 & 605 & 321 \\
\hline$P$ value & 0.949 & 0.541 & 0.393 & 0.773 & 0.577 & 0.530 & 0.162 & 0.545 & 0.752 & 0.498 \\
\hline Pooled s.e.d ${ }^{2}$ & 3.3 & 5.8 & 25.9 & 3.8 & 8.0 & 45.4 & 8.4 & 15.8 & 10.2 & 11.9 \\
\hline Cobb & 129 & 461 & 3564 & 117 & 274 & 2148 & 905 & 593 & 603 & 330 \\
\hline Ross & 132 & 468 & 3577 & 116 & 273 & 2149 & 875 & 583 & 599 & 329 \\
\hline P valu & 0.219 & 0.562 & 0.738 & 0.660 & 0.915 & 0.985 & 0.03 & 0.412 & 0.811 & 0.945 \\
\hline Pooled s.e.d ${ }^{2}$ & 2.2 & 10.7 & 36.9 & 2.4 & 9.6 & 55.9 & 10.6 & 12.0 & 14.2 & 7.7 \\
\hline
\end{tabular}

\footnotetext{
${ }^{1}$ European Efficiency factor = [BW (kg) x liveability (\%) x 100]/[feed used per kg BW (kg) x age (d)].

${ }^{2}$ Res DF $=6$.
} 
genotypes for mortality, the incidence of SDS and leg abnormalities, or tibial breaking strength (Table 2).

Table 2 Mean mortality and incidence of Sudden Death Syndrome to, and tibial breaking strength at, $35 \mathrm{~d}$ for Cobb '500' and Ross '308' males given $12 \mathrm{~h}$ bright light (12L:12D), $11 \mathrm{~h}$ bright and $1 \mathrm{~h}$ dim light (11L:1dim:12D) or $11 \mathrm{~h}$ bright with a 1-h photoperiod interrupting the night (11L:5D:1L:7D)

\begin{tabular}{lcccc}
\hline Lighting treatment & $\begin{array}{c}\text { Mortality and culling } \\
\text { (Arcsine) }\end{array}$ & $\begin{array}{c}\text { Sudden Death } \\
\text { Syndrome (Arcsine) }\end{array}$ & $\begin{array}{c}\text { Leg } \\
\text { abormalities } \\
\text { (Arcsine) }\end{array}$ & $\begin{array}{c}\text { Tibial breaking } \\
\text { strength (kg) }\end{array}$ \\
\hline 12L:12D & 0.31 & 0.11 & 0.13 & 40.4 \\
11L:1dim:12D & 0.35 & 0.13 & 0.15 & 43.0 \\
11L:5D:1L:7D & 0.40 & 0.14 & 0.18 & 42.9 \\
$P$ value & 0.167 & 0.544 & 0.368 & 0.440 \\
Pooled s.e.d ${ }^{1}$ & 0.036 & 0.023 & 0.033 & 2.07 \\
\hline Cobb & 0.36 & 0.13 & 0.16 & 41.5 \\
Ross & 0.35 & 0.12 & 0.15 & 42.7 \\
P value & 0.812 & 0.799 & 0.918 & 0.527 \\
Pooled s.e.d ${ }^{1}$ & 0.040 & 0.018 & 0.026 & 1.67 \\
\hline 1 & & & &
\end{tabular}

${ }^{1}$ Res DF $=6$.

Table 3 Mean feed intake during the first $11 \mathrm{~h}$ of bright illumination and during the subsequent mixture of 1 $\mathrm{h}$ bright or dim light and $12 \mathrm{~h}$ darkness for Cobb '500' and Ross '308' males given $12 \mathrm{~h}$ bright light (12L:12D), $11 \mathrm{~h}$ bright and $1 \mathrm{~h}$ dim light (11L:1dim:12D), or $11 \mathrm{~h}$ bright with a 1-h photoperiod interrupting the night (11L:5D:1L:7D)

\begin{tabular}{|c|c|c|c|c|c|}
\hline \multirow[b]{2}{*}{$\begin{array}{l}\text { Lighting } \\
\text { treatment }\end{array}$} & \multicolumn{2}{|c|}{ Proportion of daily feed intake (\%) } & \multicolumn{3}{|c|}{ Feed intake (g/bird) } \\
\hline & $\begin{array}{l}11 \text { h bright } \\
\text { photoperiod }\end{array}$ & $\begin{array}{l}12 \text { h of darkness } \\
\text { and } 1 \text { h of bright } \\
\text { or dim light }\end{array}$ & $\begin{array}{l}11 \text { h bright } \\
\text { photoperiod }\end{array}$ & $\begin{array}{l}12 \mathrm{~h} \text { of darkness } \\
\text { and } 1 \mathrm{~h} \text { of bright } \\
\text { or dim light }\end{array}$ & Daily total \\
\hline 12L:12D & 61.1 & 38.9 & $101^{\mathrm{b}}$ & 66 & $168^{\mathrm{b}}$ \\
\hline 11L:1dim:12D & 62.0 & 38.0 & $113^{\mathrm{a}}$ & 69 & $182^{\mathrm{a}}$ \\
\hline 11L:5D:1L:7D & 64.2 & 35.8 & $114^{\mathrm{a}}$ & 64 & $178^{\mathrm{a}}$ \\
\hline$P$ value & 0.405 & 0.405 & 0.048 & 0.498 & 0.023 \\
\hline Pooled s.e.d. ${ }^{1}$ & 2.22 & 2.22 & 4.5 & 4.3 & 4.2 \\
\hline
\end{tabular}

${ }^{1}$ Res DF $=7$.

Table 4 Mean feed intake during the first $11 \mathrm{~h}$ of bright illumination, during the final $1 \mathrm{~h}$ of bright or dim light, and during the 12-h night for Cobb '500' and Ross '308' males given $12 \mathrm{~h}$ bright light (12L:12D) or 11 $\mathrm{h}$ bright and $1 \mathrm{~h}$ dim light (11L:1dim:12D)

\begin{tabular}{lcccc}
\hline \multirow{2}{*}{ Lighting treatment } & \multicolumn{3}{c}{ Feed intake (g/bird) } & $\begin{array}{c}\text { Night-time feeding } \\
\text { (\%) }\end{array}$ \\
\cline { 2 - 4 } & 12-h day & Final 1 h of day & 12-h night & 28.7 \\
\hline 12L:12D & 119 & 17 & 49 & 28.5 \\
11L:1dim:12D & 130 & 17 & 51 & 0.958 \\
$P$ value & 0.108 & 0.852 & 0.622 & 2.7 \\
Pooled s.e.d. $^{1}$ & 5.8 & 1.1 & 4.7 & \\
\hline${ }^{1}$ Res DF $=4$ & & &
\end{tabular}


There were no significant effects of lighting treatment on the proportion of the daily feed intake consumed during the first $11 \mathrm{~h}$ of the main photoperiod nor on the proportion of feed eaten during the ensuing $13 \mathrm{~h}$, irrespective of whether the $1 \mathrm{~h}$ of light simply extended the 11-h photoperiod to $12 \mathrm{~h}$ (bright or dim illuminance) or was given at bright illuminance in the middle of the night (Table 3). However, the birds given a 1-h dusk or a 1-h night interruption photoperiod consumed significantly more feed in the first $11 \mathrm{~h}$ of the main photoperiod and in total for the $24 \mathrm{~h}$ than did the 12L:12D birds, though the quantities of feed eaten in the 13-h 'night' was not significantly different for the three groups (Table 3). Whilst reducing the illuminance in the $12^{\text {th }}$ hour of the main photoperiod to simulate dusk had no significant effect on the amount of feed consumed during this final hour (Table 4), there was a highly significant $(\mathrm{P}<0.001)$ faster rate of eating during the final hour $(17.3 \mathrm{~g} / \mathrm{h})$ than during the preceding $11 \mathrm{~h}$ of illumination $(9.7 \mathrm{~g} / \mathrm{h})$ by both the 12L:12D and 'Dim' birds. The illuminance during the final hour of the photoperiod had no effect on the amount of nocturnal feeding activity (Table 4). Note there were no data for the 12th hour for the 'night-interruption' birds because they were in darkness at the time and so feed weigh-backs were not practical.

\section{Discussion}

Mean body weights at $35 \mathrm{~d}$ for Cobb (2 $190 \mathrm{~g}$ ) and Ross (2 $198 \mathrm{~g}$ ) birds were 35 and $25 \mathrm{~g}$ respectively above the primary breeder body weight targets, and this, despite $12 \mathrm{~h}$ being the only photoperiod, supports the findings of Lewis et al. (2009a) that $12 \mathrm{~h}$ light is adequate for achieving optimal growth in modern broilers. This is in contrast to the earlier findings that growth is suboptimal for broilers reared on $12 \mathrm{~h}$ (e.g. Brickett et al., 2007). One of the reasons for this apparent change in the broiler's photoperiodic response is its acquired ability to eat during the dark period (Lewis et al., 2008; 2009a). The lack of significant differences in performance between the three lighting treatments, especially during the initial $14 \mathrm{~d}$, shows that providing a 1-h 'dusk' or 1-h night-interruption photoperiod affords no significant improvement in feed intake, growth, feed conversion efficiency or liveability to $35 \mathrm{~d}$. Notwithstanding that the larger feed intakes (2.41/2.41 vs. $2.36 \mathrm{~kg})$ and body weight gains (1.30/1.32 vs. $1.25 \mathrm{~kg})$ during the 22 to $35 \mathrm{~d}$ period for the two novel lighting treatments relative to the control birds failed to reach statistical significance, the effects may have been real because during the two 24-h periods in which feeding patterns were monitored these two groups ate significantly more feed than the conventional 12-h group (Table 3).

Although these findings contradict those of Savory (1976) that 'dusk' encourages a bird to consume more feed at the end of the day in anticipation of night-time starvation, the original work was conducted more than 30 years ago when, as Savory himself noted, broilers did not eat during the night of a 12L:12D regimen. The modern broiler exposed to 12 -h photoperiods eats in excess of $20 \%$ of its daily feed intake in the dark, so does not expect a period of starvation (Table 4 and Lewis et al., 2009a). Another reason may be that in the Savory study birds received both a 'dawn' and 'dusk', with the latter lasting for $2 \mathrm{~h}$ and involving a gradual decrease in illuminance; in the current study 'dusk' lasted only an hour and was provided at a steady illuminance. The disparity of our findings with those of Classen et al. (2004) might be attributed to the difference in the type of lighting regimen. In the current trial, birds given the night-interruption treatment could still form a day and night, despite having two periods of darkness, because one was $2 \mathrm{~h}$ longer than the other, but in the Classen study, the fragmented dark periods were of equal size (1L:1D or 6L:6D) and so the birds were unable to form a day and night and rhythmically free-ran. Under such short-cycle regimens broilers perform meal-feeding, and this has been reported to stimulate growth and improve feed conversion, especially in males (Buyse et al., 1996). On the other hand, it may simply be that when a bird is performing to its potential, as seems likely for the 12-h birds in this study, there is little room for further improvement. With no significant effects of lighting regimen on feed intake, growth, liveability, the incidence of leg problems or night-time feeding (and presumably locomotor activity) it is perhaps not surprising that the novel lighting regimens had no effect on tibial breaking strength.

In contrast, the feeding patterns are surprising and difficult to explain. One might have expected the change in illuminance in the final hour of the photoperiod to have had some influence on feed intake, yet this did not occur (Table 4). Equally unexpected was the similarity of feed intake during the $13 \mathrm{~h}$ of mixed light and darkness following the first $11 \mathrm{~h}$ of the main photoperiod, irrespective of the location or illuminance of the extra $1 \mathrm{~h}$ of light. More abstruse, is the higher feed consumption of the 'dusk' and night-interruption groups during the 11-h brightly illuminated photoperiod when all three groups were illuminated the same. 
The proportion of nocturnal feeding was similar to that reported by Lewis et al. (2009a) for 12-h birds, thus confirming the willingness of the modern broiler to eat during the night when given a photoperiod which otherwise would be too short to satisfy its appetite.

In conclusion, there appears to be nothing to be gained from providing a 1-h 'dusk' or nightinterruption photoperiod to broiler males exposed to 12-h photoperiods, at least when they are maintained according to the management protocols applied in this study.

\section{Acknowledgements}

The authors acknowledge the financial contribution of the Protein Research Foundation to this study, Ross Poultry (South Africa) for the donation of day-old chicks, Cobb S.A. for subsidising the cost of day-old chicks, and Ann Kinsey for her assistance in conducting the study. The study was supported by the Ministry of Education, Youth and Sports of the Czech Republic (Project No. 6046070901).

\section{References}

Analytical Software, 2003. StatistixVersion 8, Tallahassee, FL 32317, USA.

Brickett, K.E., Dahiya, J.P., Classen, H.L. \& Gomis, S., 2007. Influence of dietary nutrient density, feed form, and lighting on growth and meat yield of broiler chickens. Poult. Sci. 86, 2172-2181.

Buyse, J., Simons, P.C.M., Boshouwers, F.M.G. \& Decuypere, E., 1996. Effect of intermittent lighting, light intensity and source on the performance and welfare of broilers. Wrld's Poult. Sci. J. 52, 121-130.

Classen, H.L., Annett, C.B., Schwean-Lardner, K.V., Gonda, R. \& Derow, D., 2004. The effects of lighting programmes with twelve hours darkness per day provided in , one, six or twelve hour intervals on the productivity and health of broiler chickens. Br. Poult. Sci. Suppl. 45, S31-32.

Ingram, D.R., Hatten III, L.F. \& McPherson, B.N., 2000. Effects of light restriction on broiler performance and specific body structure measurements. J. Appl. Poult, Res. 9, 501-504.

Lewis, P.D., Danisman, R. \& Gous, R.M., 2008. Male broiler performance and nocturnal feeding under constant 8-h or 16-h photoperiods, and various increasing lighting regimens. S. Afr. J. Anim. Sci. 38, 159-165.

Lewis, P.D., Danisman, R. \& Gous, R.M., 2009a. Photoperiodic responses of broilers: I. Growth, feeding behaviour, breast yield, and testicular growth. Br. Poult. Sci. 50, 657-666.

Lewis, P.D., Danisman, R. \& Gous, R.M., 2009b. Photoperiodic responses of broilers: III. Tibial breaking strength and ash content. Br. Poult. Sci. 50, 673-679.

Savory, C.J., 1976. Broiler growth and feeding behaviour in three different lighting regimes. Br. Poult. Sci. $17,557-560$.

Sqibb, R.L. \& Collier, G.H., 1979. Feeding behavior of chicks under three lighting regimens. Poult. Sci. 58, 641-645. 